PROCESO DE INTEGRACIÓN

DE LAS INCORPORACIONES LÉXICAS EN ESPAÑOL: ASPECTOS TEÓRICOS Y PRESENCIA LEXICOGRÁFICA

INTEGRATION PROCESS OF LEXICAL INCORPORATIONS IN SPANISH: THEORETICAL ASPECTS AND LEXICOGRAPHICAL PRESENCE 
Los hablantes cuando usan la lengua no se plantean cómo son las palabras que utilizan o cuál es su procedencia. Sin embargo, son conscientes de que determinadas voces son de reciente incorporación puesto que presentan unas características que son idénticas o más afines a otros idiomas (notebook, baguette, playboy, sushi, match, celebrity, wifi, párking, esmoquin, spam, selfie...). En el transcurso del tiempo, estas palabras pueden llegar a integrarse en la lengua (en este caso, la española) con o sin adaptación en función de las diferencias existentes entre el idioma de origen y el receptor o de la mayor o menor aceptación del término extranjero. Si esto ocurre, los hablantes dejarán de ser conscientes, de un modo progresivo, de la procedencia foránea de estas voces del mismo modo que sucedió con acuarela, restaurante, piano o voleibol, entre otras, que en su momento también fueron desconocidas para quienes empezaron a utilizarlas.

El objetivo del presente artículo consistirá en analizar los conceptos teóricos relacionados con la transmisión léxica. También se demostrará que se produce un proceso de integración equivalente a la progresiva pérdida de conciencia por parte de los hablantes de la procedencia extranjera de las voces incorporadas de otras lenguas, hayan o no sufrido algún tipo de adaptación. Desde el punto de vista práctico, se evidenciará dicho proceso a partir de la presencia lexicográfica de estas palabras en diccionarios normativos y de uso.

Palabras clave: lexicología, lexicografía, contacto de lenguas

When speakers make use of a language, they don't think about how the words are used or where they come from. However, they are conscious that some terms are recently imported because the formal characteristics that they show are identical or more similar to what can be found in other languages (notebook, baguette, playboy, sushi, match, celebrity, wifi, párking, esmoquin, spam, selfie...). Over the course of time, these words can be integrated into the language (in this case into the Spanish language), with or without a greater or lesser degree of acceptance. If this happens, speakers will progressively stop being conscious of the foreign origin of these words in the same way that occurred with acuarela, restaurante, piano or voleibol, among others, that in the past had also been unknown for those who began to use them.

The aim of the present paper will consist on analysing the theoretical concepts related to lexical transmission. Besides, it will also show that it takes place an integration process equivalent to the progressive loss of conscience by the speakers of the foreign origin of the words received from other languages. From a practical point of view, the mentioned process will be demonstrated from the analysis of the presence of this kind of terms in normative dictionaries or in the ones that show the use of words.

KEYwORDs: lexicology, lexicography, languages in contact

FECHA DE RECEPCIÓN: 4/12/2015

FECHA DE ACEPTACIÓN: 03/02/2016 


\title{
PROCESO DE INTEGRACIÓN DE LAS INCORPORACIONES LÉXICAS EN ESPAÑOL: ASPECTOS TEÓRICOS Y PRESENCIA LEXICOGRÁFICA ${ }^{1}$
}

\author{
INTEGRATION PROCESS OF \\ LEXICAL INCORPORATIONS IN \\ SPANISH: THEORETICAL ASPECTS \\ AND LEXICOGRAPHICAL PRESENCE
}

Marta Prat Sabater

Universitat Autònoma de Barcelona

\section{Introducción}

La entrada de nuevas palabras en una lengua es un hecho imparable, puesto que se produce desde los inicios de su existencia y se perpetúa indefinidamente, producto del contacto lingüístico entre comunidades de habla distinta. Sin embargo, en el terreno lexicológico este proceso suele interpretarse conceptualmente sin vinculación explícita con las perspectivas sincrónica y diacrónica. En este artículo,

\footnotetext{
${ }^{1}$ La presente investigación ha sido parcialmente financiada con ayuda del Ministerio de Economía y Competitividad para los proyectos "Historia interna del Diccionario de la lengua castellana de la Real Academia Española en el siglo XIX (1817-1852)" (no de referencia FFI2014-51904-P) y "El español en contacto con el catalán: variación diatópica y bilingüismo" ( $n^{\circ}$ de referencia FFI201233499), junto con el apoyo de la AGAUR de la Comissió Executiva d’Ajuts de Recerca de la Generalitat de Catalunya (nº de referencia 2014 SGR 1328).
} 
dividido en dos apartados principales, se pretende demostrar la importancia de la relación entre los dos enfoques citados, la incorporación de elementos léxicos en una lengua y el uso que de ellos hacen los hablantes.

La parte teórica se centra en analizar y valorar los términos lingüísticos relativos a la denominación del proceso de importación de voces ajenas al español, determinar de un modo específico la importancia del empleo de los conceptos extranjerismo y préstamo léxico, del mismo modo que consolidarlos, respectivamente, con un estado puntual de la lengua referente al presente de cualquier momento histórico y la consecuencia de un estado evolutivo. Por esta razón, la entrada de extranjerismos se sitúa en el punto inicial (sincronía) de un proceso continuo que con el paso del tiempo y las posibles adaptaciones lingüísticas (o no) que puedan producirse culmina con un resultado diacrónico (préstamos léxicos). Existe, además, una relación directa con la percepción de los hablantes: una palabra se desprende progresivamente de sus condicionantes foráneos para llegar a considerarse propia de la lengua receptora. En este momento es cuando puede afirmarse que se ha culminado el proceso deintegración.

La parte práctica se fundamenta en verificar la aplicación de dicho proceso en la lexicografía. En la fase inicial, puede ocurrir que no aparezca la palabra en el diccionario (selfie) o que esté presente solo con mantenimiento de la forma gráfica extranjera (chalet, scooter, paddel o pizza). En siguientes fases (ediciones posteriores de un mismo diccionario), pueden hallarse nuevas entradas previamente ausentes $(b \log )$, modificaciones de las formas de los lemas para reflejar que el proceso de adaptación ha terminado (chalé, 
escúter o pádel), ejemplos de invariabilidad por no haberse producido ningún tipo de cambio ( $p i z z a)$, ejemplos de vacilación en diferentes ediciones por no tener clara la forma definitiva (criquet $\rightarrow$ cricket $\rightarrow$ críquet) o remisiones a otras palabras propias de la lengua (roulotte $\rightarrow$ caravana). El punto culminante consistirá en valorar en qué momento estas ampliaciones lexicológicas coinciden con el final del proceso de integración y, por lo tanto, deja de percibirse, por parte de los hablantes, el valor extranjero de lo que en un primer momento fueron nuevas palabras.

\section{Incorporación de voces en el léxico de una lengua}

El término neologismo designa cualquier elemento léxico nuevo en una lengua. Sin embargo, para la formación de nuevas palabras hay diferentes recursos: los mecanismos internos del propio sistema lingüístico o las incorporaciones externas de otros idiomas. Al tratarse de un hiperónimo que abarca tanto cuestiones formales como de contenido de distintas características, no va a ser el que se utilice en el presente artículo puesto que, según se ha comentado en el apartado anterior $(\$ 1)$, el tema que va a tratarse se refiere a las influencias léxicas que se advierten en el contexto del contacto de lenguas. Por esta razón, en el siguiente apartado (\$2.1.) se discutirá el metalenguaje más adecuado para designar las voces que el español importa o ha importado de lenguas extranjeras, directamente relacionado, según se demostrará, con el proceso de integración de carácter interlingüístico (\$2.2). 


\subsection{Extranjerismo y préstamo: variabilidad de designaciones lingüísticas}

La investigación lexicológica ha proporcionado diferentes términos a lo largo del siglo $\mathrm{xx}$ para distinguir las voces foráneas que, por razones tanto lingüísticas como extralingüísticas, cualquier lengua puede recibir o haber recibido de otra.

El punto de partida del término préstamo debemos situarlo en las dos principales corrientes vinculadas con el contacto de lenguas: la tradición norteamericana y la tradición europea. La primera de ellas nace del estructuralismo descriptivista que, tomando como base las ideas de Saussure, considera que "la lingüística no consiste sino en la descripción del sistema de lengua, es decir, de su estructura, partiendo de la noción de paradigma, y siempre desde una perspectiva sincrónica" (Villar Díaz, 2009: 224). Si lo contextualizamos en el terreno lexicológico, el concepto de estructura muestra una dependencia directa de la idea de relación léxica, claramente vinculada con la semántica (cf. Villar Díaz, 2009: 231). El término propio que utilizan los estructuralistas para la incorporación de palabras en una lengua es el de importación, basado principalmente en la importación morfémica (cf. Gómez Capuz, 2004: 52 y 2005: 13). Más adelante, esta concepción se renovará con las ideas del distribucionalismo representado por Bloomfield, quien tiene más en cuenta la perspectiva diacrónica y menos la semántica. En este contexto, debemos situar los estudios de bilingüismo y multilingüismo, cuyos principales impulsores, Haugen (1950) y Weinreich (1953), explican, desde el pun- 
to de vista léxico, las consecuencias de una relación directa entre diferentes lenguas. Según Haugen (1950: 212), "the heart of our definition of borrowing is [...] the attempted reproduction in one language of patterns previously found in another $[\ldots]$. The term reproduction does not imply that a mechanical imitation has taken place; on the contrary, the nature of the reproduction may differ very widely from the original".

A esta definición de borrowing, no restringida al proceso de imitación, sino vinculada incluso al de diferenciación formal de los elementos léxicos que se transmiten, Weinreich (1953: 54) agrega una precisión sobre el grado en que puede afectar al vocabulario de la lengua receptora: "Except for loanwords with entirely new content, the transfer or reproduction of foreign words must affect the existing vocabulary in one of three ways: (1) confusion between the content of the new and old word; (2) disappearance of the old word; (3) survival of both the new and old word, with a specialization in content". Según detalla el autor, la incorporación de palabras de procedencia extranjera - aunque no exclusivamente- con conceptos no desconocidos, no solo puede consistir en provocar la desaparición de una palabra integrada en el vocabulario de la lengua receptora (uso actual de sastre en lugar de alfayate), sino una confusión entre el contenido de la palabra ya existente y la nueva (óleo y aceite) o incluso la supervivencia de ambas aunque una de ellas solo se mantiene en el lenguaje especializado (mirar y catar 'ver, observar' > 'probar').

Independientemente de las explicaciones conceptuales de ambos lingüistas, se puede observar, desde los inicios, 
en el ámbito de la lengua inglesa, la utilización de dos términos, borrowing y loanword, al igual que ocurre en alemán (Entlehnung y Lehnwort), para designar la transferencia léxica. En español, en cambio, el metalenguaje se manifiesta, de entrada, más simplificado puesto que ambos términos podrían traducirse como préstamo, al igual que en la mayoría de lenguas románicas para las que también se dispone de una sola palabra (fr. emprunt o it. prestito, por ejemplo). Mientras que en las lenguas germánicas se lleva a cabo la distinción entre proceso de transmisión (borrowing o Entlehnung) y elemento transmitido (loanword y Lehnwort), en las románicas ambas ideas se restringen a un solo término (préstamo, emprunt o prestito, según se ha ejemplificado). ${ }^{2}$

Los antecedentes de la tradición europea deben buscarse en las corrientes comparatistas e historicistas de principios del siglo xx. A diferencia de los enfoques norteamericanos, destaca en ellas la priorización de la vertiente diacrónica por cuanto a influencia entre lenguas se refiere. Se tienen en cuenta, por lo tanto, cuestiones de tipo histórico, cultural y social, lo que supone un mayor interés por la semántica. Uno de los primeros representantes de la tradición europea es Deroy. Este lingüista toma como punto de partida la definición básica de préstamo de Pisani (1939), "l'emprunt est une forme d'expression qu'une communauté linguistique reçoit d'une autre communauté" (apud Deroy, 1956: 18), a la que añade la precisión de que "le mot emprunté apporte avec lui des éléments grammaticaux qui secondairement se développent de façon autonome" (1956: 21). Desde la perspecti-

${ }^{2}$ Cf. Gómez Capuz (1998: 19) y Álvarez de Miranda (2009: 143). 
va semiótica, Rey-Debove ofrece una posterior aportación más completa y, al mismo tiempo, restrictiva puesto que ya incorpora el adjetivo léxico al concepto de préstamo, que define del siguiente modo: "l'emprunt lexical au sens strict est l'emprunt d'un signe étranger, expression et contenu (l'un et/ou l'autre pouvant être légèrement altérés, mais non pas différents" (1973: 110). Sin embargo, no se conforma exclusivamente con la definición general de préstamo léxico que propone, sino que particulariza lo que ocurre durante el proceso de transmisión:

On appelle emprunt lexical au sens strict le processus par lequel une langue L1, dont le lexique est fini et déterminé dans l'instant $\mathrm{T}$, acquiert un mot M2 (expression et contenu) qu'elle n'avait pas, et qui appartient au lexique d'une langue L2 (également fini et déterminé dans l'instant $\mathrm{T}$ ). Ce processus se déroule de l'instant $\mathrm{T}$ à l'instant T'; le temps écoulé entre T et T' est très variable et correspond à la codification plus ou moins rapide d'un fait de discours dans la langue (1973: 110).

De esta explicación se desprende que el proceso de transferencia de un elemento léxico debe interpretarse desde el punto de vista diacrónico puesto que entre el punto inicial y final hay un espacio temporal más o menos extenso; sin embargo, el momento T implica un estado sincrónico que, según se demostrará en este artículo, no solo debe ser actual o reciente, sino que también puede ser lejano en el tiempo.

Ante este breve repaso histórico, es evidente que el concepto de préstamo, sin más, se constituye como hiperónimo, interpretable desde diversas vertientes teóricas vinculadas 
a diferentes ramas específicas del saber en función de la perspectiva que se adopte en su uso. Esta especificación queda reflejada en los adjetivos que acompañan al sustantivo y que forman los diferentes hipónimos.

El propio Bloomfield y los descendientes del distribucionalismo han utilizado, según detalla Gómez Capuz (2004: 17-34), tres tipos de designaciones: préstamo dialectal o interno, préstamo cultural y préstamo intimo. El primero de ellos no está integrado en los objetivos de este artículo puesto que hace referencia a las variedades diatópicas, diastráticas y diafásicas de una misma lengua, es decir, a las influencias que puedan ejercer sobre los demás los dialectos que gozan de mayor prestigio o los grupos sociales más elevados (cf. también Gómez Capuz, 1998: 23-26). Esto ha conllevado a que se emplee una nomenclatura aún más específica como préstamo diatópico o dialectal (entre dialectos), préstamo diatécnico (de la lengua especializada a la lengua común) y préstamo diastrático o social (entre grupos sociales).

El préstamo cultural está, al mismo tiempo, relacionado con la tradición europea y contextualizado en la sociolingüística. Se trata del intercambio de novedades entre lenguas, no exclusivamente léxicas, que se encuentran en el mismo nivel de consideración, aunque una de ellas puede destacar más que otra en diferentes aspectos (musical, pictórico, gastronómico, científico, etc.). En este apartado entrarían los anglicismos, galicismos, italianismos o lusismos del español, por ejemplo, según la concepción de Bloomfield que, en este sentido, equipara lengua y nación. También se han llegado a denominar préstamos históricos o antiguos, es decir, no percibidos por los hablantes como foráneos, para 
distinguirlos claramente de los extranjerismos o incorporaciones más recientes de cualquier lengua.

Desde el enfoque de Bloomfield, los préstamos intimos deben interpretarse como intercambios que se producen entre lenguas que comparten un mismo territorio político y en los que una de ellas (la oficial en todo el territorio) suele ser superior a las demás como, por ejemplo, el español frente al catalán, el gallego o las lenguas amerindias de Hispanoamérica. Es evidente que este punto de vista está directamente relacionado con los conceptos de bilingüismo y diglosia. Es muy probable que sea esta la razón por la que Weinreich adoptara la denominación de interferencia, más precisa, mejor fundamentada e interpretable de un modo espacial no tan restringido.

En realidad, la justificación del uso de préstamo intimo de Bloomfield se basa en el concepto de jerarquización de una lengua respecto a otra con el que hacía especial referencia a los inmigrantes extranjeros de Estados Unidos o, en el caso del español, podría pensarse en su relación con las lenguas indígenas de Hispanoamérica (náhuatl, guaraní, quechua, etc.). Sin embargo, a mi modo de ver, resulta muy discutible la distinción entre préstamo cultural e íntimo puesto que, en el contexto de las lenguas románicas, por ejemplo, diferentes factores históricos pueden poner en duda la distribución de catalanismos o galleguismos en un grupo distinto del de los lusismos, galicismos e italianismos. En este sentido, resulta esencial tener en cuenta la diacronía, es decir, los diferentes momentos históricos de cada lengua y no solo el valor sincrónico que en la actualidad, o en la primera mitad del siglo $\mathrm{xx}$, podían tener. 
Si se interpreta el concepto de préstamo en oposición a extranjerismo, pueden destacarse otro tipo de denominaciones, cuyo punto inicial se halla en las corrientes formalistas alemanas de la primera mitad del siglo XIX, representadas por Betz (1949), quien "investigó las influencias del latín eclesiástico en las traducciones de la Biblia realizadas en gótico y antiguo alto alemán, lenguas carentes de la terminología precisa para designar los nuevos conceptos cristianos" (apud Gómez Capuz, 2004: 35). Los criterios de este autor se basan, desde el punto de vista sociolingüístico, en la consideración del latín como lengua modelo que "no se interpreta tanto como lengua extranjera sino más bien como lengua de referencia o «lengua patrón», vehículo de una cultura superior que debe ser imitada" (Gómez Capuz, 2004: 35). Sobre esta base, establece la tipología de préstamos en tres categorías: préstamo integral, calco léxico o estructural y préstamo semántico.

El primero de ellos, que es el que interesa para este artículo y sobre el que se prestará atención en las siguientes líneas, lo subdivide en dos grupos, Fremdwort y Lehnwort (términos equivalentes a extranjerismo y préstamo, respectivamente), según el nivel de asimilación formal que manifiestan respecto a la lengua receptora (cf. también Gómez Capuz, 1998: 31 y 2005: 14; Álvarez de Miranda, 2009: 143). Si se acepta esta concepción de préstamo integral de Betz, también denominada total por Deroy (1956), debe relacionarse directamente con los diferentes procesos de adaptación, que permiten justificar la oposición que realiza Seco (1977: 197) entre préstamo y extranjerismo: "hay que distinguir entre las voces extranjeras que el idioma ha asimilado totalmente a su sistema, voces ya «digeridas» por la lengua, que son los préstamos pro- 
piamente dichos, y las palabras que en su grafía, o en su pronunciación, o en ambas cosas a la vez, acusan en los hablantes una conciencia de que emplean una palabra extranjera, voces que todavía se sienten «enquistadas» en el idioma: son los extranjerismos". Para ello, Gómez Capuz (2005: 14-27) propone tres etapas de integración (importación de un extranjerismo, proceso de asimilación y madurez). Con el fin de explicar la primera, utiliza una designación más concreta, préstamo cultural, coincidente con la que ya propuso Bloomfield y comentada con anterioridad, que consiste en la incorporación de otra lengua de elementos léxicos de todo tipo, pero, en este caso, se contextualiza mayoritariamente en el terreno de los lenguajes especializados ( $D J$ 'pinchadiscos'; match 'partido'; fair play 'juego limpio'; cool 'genial'; selfie, usado en el compuesto sintagmático palo selfie; etc.). Estas incorporaciones pueden producirse por omisión léxica o simplemente porque una lengua presenta una influencia considerable sobre la receptora y le transmite una palabra que podríamos llamar innecesaria puesto que coincide semánticamente con otra que ya posee.

En el ámbito del español, se hallan también otras denominaciones equivalentes no tanto a préstamo cultural, aunque sí al concepto general de extranjerismo - algunas adaptadas de autores franceses- que podrían tener cabida dentro de esta primera etapa: peregrinismo (cf. Lázaro Carreter, 1987: 36; Alvar Ezquerra, 1999a: 56 y 1999b: 213), palabra-cita (cf. Alvar Ezquerra, 2006 [1994]: 17), que lo traduce del francés citation, préstamo crudo (Álvarez de Miranda, 2009: 143), extranjerismo crudo (NGLE \$3.4c) y, en referencia a una lengua concreta, anglicismo patente (Pratt, 1980: 116), cuando se 
hace referencia a voces extranjeras introducidas por omisión léxica; xenismo (cf. Lázaro Carreter, 1987: 36; Guerrero-Ramos, 1997 [1995]: 37 y 2013: 120; Alvar Ezquerra, 1999a: 56 y 1999b: 209; Lázaro Carreter, 2003: 24), relativo a voz extranjera innecesaria por tener que competir con equivalencia autóctona de la lengua receptora; o, incluso, barbarismo (Medina López, 2004 [1996]: 15). ${ }^{3}$ Sea cual sea el término con que se identifiquen, todas ellas se caracterizan, principalmente, por la identidad formal, aunque no siempre semántica en su totalidad, con el étimo de la lengua trasmisora y por utilizarse, en la mayoría de casos, de forma más o menos esporádica.

La segunda etapa de integración - la más extensa desde el punto de vista temporal- hace referencia al proceso de asimilación del extranjerismo y para ello debe pasar, según Gómez Capuz (2005: 17), por diferentes fases (adaptación, asimilación y naturalización). Este proceso consiste en amoldar las palabras incorporadas en la primera etapa a las condiciones de la lengua receptora, principalmente gráficas, fonéticas y/o morfológicas, según las necesidades que manifieste el elemento léxico o, dicho de otro modo, según el grado de diferenciación que pueda existir entre las lenguas implicadas: ketchup (< ingl.) $\rightarrow$ kétchup, croissant $(<$ fr. $) \rightarrow$ cruasán o abertzale (< vasco) $\rightarrow$ aberzale. ${ }^{4}$ La influencia del

\footnotetext{
${ }^{3}$ El término barbarismo puede llevar a confusión puesto que no es exclusivo para indicar el uso inadecuado de una determinada palabra por su condición de extranjerismo, sino que se aplica también a cualquier "transgresión de la norma de un determinado sistema lingüístico” (Gómez Capuz, 1998: 52), por lo tanto, no se considera adecuado para los objetivos de este trabajo ni oportuno para equipararlo a extranjerismo.

${ }^{4}$ Para datos más exhaustivos de estas y otras voces y de los diferentes procesos de adaptación, véase Prat Sabater y Buenafuentes de la Mata (2008). Según po-
} 
inglés, por ejemplo, es muy significativa en Hispanoamérica e incluso en comunidades españolas de Estados Unidos. Appel y Muysken (1996: 253) lo ejemplifican con la variedad costarricense en la que se utiliza chinchibi 'cerveza de jenjibre' (< ingl. ginger beer) o espich 'discurso' (< ingl. speech) a lo que podría añadirse, relacionado con comunidades españolas de Tejas, según Sala (1998: 236), esteche 'camión' (< ingl. stage wagon). Otros ejemplos de ámbito hispanoamericano son más generales y están contemplados por la propia RAE (2014) en la última edición de su diccionario, como teléfono celular (< ingl. amer. cellular phone) frente al teléfono móvil en España (< ingl. brit. mobile phone). El objetivo último es el de conseguir un buen asentamiento de los nuevos términos entre los hablantes y una amplitud de uso, a nuestro modo de ver, no solo técnico, sino incluso cotidiano. Desde el punto de vista de Hjelmslev (1966), este proceso crea mots demprunt (apud Sala, 1998: 230), equivalente a la designación española de préstamos o, lo que es lo mismo, pierden progresivamente su condición de neologismo (cf. Guilbert, 1975: 95). Es importante tener en cuenta, sin embargo, que no todas las voces superan esta etapa y mantienen, según Hjelmslev, su condición de mots étrangers (apud Sala, 1998: 230) o lo que en español conocemos con el término habitual de extranjerismos. Esta reticencia a posibles cambios, generalmente favorecida por la actitud de los hablantes frente a propuestas académicas de adaptación (cf. whisky y güisqui), implica que sigan instalándose o permaneciendo en la lengua con su forma inicial

drá observarse, además, es posible que el proceso de adaptación se produzca, pero que no quede recogido como tal por todas las fuentes lexicográficas. 
(show). También es posible que desaparezcan de ella (Bock 'jarro de cerveza' < al.); ${ }^{5}$ es decir, que se trate simplemente de presencias pasajeras, generalmente por razones de moda, y, por lo tanto, que se sustituyan en breve por otros extranjerismos o, de lo contrario, se mantengan las respectivas equivalencias autóctonas si se dispone de ellas.

En la tercera y última etapa ya no debe hablarse de extranjerismos, según Gómez Capuz (2005: 25), sino de préstamos puesto que, al hallarse completamente adaptados a la lengua receptora, ya pasan desapercibidos por los hablantes y no se detectan como elementos léxicos extraños, sino que se encuentran al mismo nivel que las voces patrimoniales. En estas condiciones, es posible aplicarles los mecanismos propios de cualquier lengua como los derivativos o compositivos, por ejemplo, lo que demuestra su perfecta integración en el idioma que los ha acogido y su posterior explotación: líder $(<$ ingl. leader $) \rightarrow$ liderar, liderato, liderazgo.

De acuerdo con los propósitos de este artículo resulta imprescindible unificar criterios y escoger la terminología que se adapta mejor a las consecuencias léxicas derivadas del contacto de lenguas y vinculadas, según se demostrará más adelante, con los procesos de integración (véase \$2.2.). En relación con lo que se ha comentado hasta el momento y según puede observarse en el Esquema 1, deben distinguirse, a nuestro modo de ver, dos bloques distintos encabezados con los conceptos de interferencia (Weinreich) y préstamo integral (Betz). El primero, cuyo contenido excede los objetivos de este trabajo,

\footnotetext{
${ }^{5}$ Esta palabra, de procedencia alemana, aparece en los diccionarios manuales de la RAE del siglo xx $(1927,1950,1983$ y 1989) y en las ediciones del DRAE de 1992 y 2001, mientras que ya no figura en el DLE 2014.
} 
deriva de lo que inicialmente Bloomfield interpretaba como préstamo íntimo, y estaría vinculado con los contextos de bilingüismo y multilingüismo de un mismo territorio. En este sentido destacaría, principalmente, por su condición sincrónica. El segundo, por su parte, no solo deriva del concepto de préstamo cultural según la interpretación de Bloomfield que equiparaba lengua y nación, sino que incluso puede ser consecuencia de lo que inicialmente podría haberse considerado interferencia, que no deja de ser incorporación foránea susceptible de integrarse de forma progresiva en la lengua receptora. Se trata, por tanto, de un concepto general que permite englobar los extranjerismos y préstamos léxicos, representantes de las perspectivas sincrónica y diacrónica. El concepto de extranjerismo, a su vez, engloba las nociones de peregrinismo y xenismo en función de si se hace referencia a incorporaciones léxicas imprescindibles o superfluas, respectivamente.

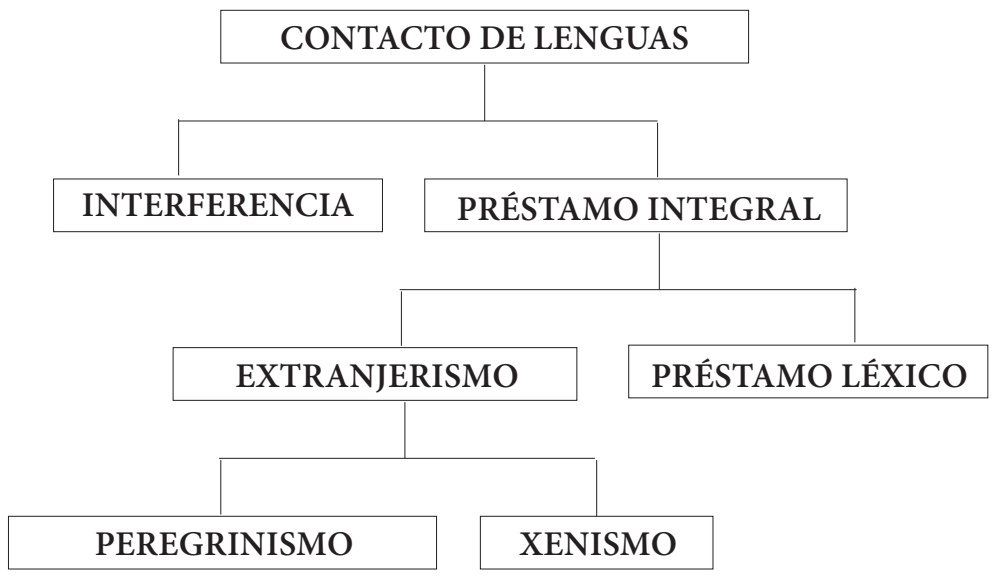

Esquema 1. Clasificación conceptual de interferencia y préstamo integral 


\subsection{Proceso de integración}

La distinción entre sincronía y diacronía no debe estar vinculada con el presente y el pasado respectivamente, sino que es complementaria en cualquier época. En las diferentes etapas históricas siempre puede hablarse de un momento puntual (o actual si nos desplazamos en el tiempo) y de una suma de cambios sucesivos que ha configurado la lengua o cualquier otra disciplina hasta el estado en el que se encuentra. Esta perspectiva es aplicable al terreno de contacto de lenguas, en general, y de los préstamos integrales en particular. Desde el punto de vista práctico, se analizará en el siguiente apartado (\$3) la presencia de dicho proceso en la lexicografía académica y en un diccionario de uso (el CLAVE). Se hará especial incidencia en las diferentes opciones de importación léxica relacionables con el pasado y el presente.

En referencia al préstamo integral, se han comentado, desde la perspectiva contemporánea, los diferentes mecanismos de adaptación que permiten integrar un extranjerismo dentro de la propia lengua hasta que su origen foráneo llega a pasar desapercibido por parte de los hablantes. Es en ese momento cuando se le suele conceder el nombre de préstamo. Sin embargo, según se ha expuesto, no todas las voces importadas sufren cambios puesto que, en función de la lengua de la que procedan, pueden presentar un grado mayor o menor de similitud con la que las recibe y, aunque la diferencia sea manifiesta, por motivos más extralingüísticos que lingüísticos, los hablantes no siempre están de acuerdo con las propuestas académicas que se proponen (cf. el clásico ejemplo de güisqui frente a whisky) y como usuarios son 
los que, al fin y al cabo, en determinadas ocasiones tienen, de modo inconsciente, la última palabra. Esta situación, que suele ejemplificarse desde el punto de vista contemporáneo, es extrapolable, según se demostrará mediante contenidos lexicográficos (véase \$3), a cualquier momento histórico. La influencia interlingüística se produce siempre desde el momento en que una lengua empieza a existir hasta que desaparece; por lo tanto, en el contexto lexicológico, lo que se presenta como proceso de adaptación, sea o no factible, no deja de ser un proceso de integración. Es decir, desde el momento en que un elemento léxico (extranjerismo) entra en una determinada lengua (punto sincrónico), empieza su historia en un entorno lingüístico nuevo, cuyo punto final no será otro que un resultado diacrónico (préstamo léxico), según queda ilustrado del cuadro 1.

\section{Proceso de integración}

EXTRANJERISMO

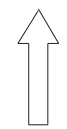

punto sincrónico

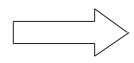

resultado diacrónicro
PRÉSTAMO LÉXICO

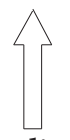

Cuadro 1. Proceso de integración

El espacio temporal del proceso de integración puede ser más o menos extenso en función de muchos factores poco predecibles como el grado de aceptación de la nueva palabra, el índice de frecuencia con que se utilice y la posible 
competencia léxica que posea, bien con voces autóctonas de la lengua receptora, bien con otros extranjerismos.

\section{Incorporación de voces: presencia lexicográfica}

El objetivo de las obras lexicográficas generales consiste en ofrecer, desde el punto de vista lexicológico, las palabras consolidadas que se utilizan en una determinada lengua. Se pretende facilitar a los distintos hablantes la información que se dispone de cada uno de los lemas escogidos; sin embargo, según podrá observarse, las decisiones pueden variar en función de si se trata de obras normativas (definitorias) o descriptivas (de uso).

La incorporación de voces forma parte de una de las tareas esenciales de los lexicógrafos, cuya dificultad principal reside en si deben incluirse o no todas las que se usan en el momento de la elaboración del diccionario o, en caso negativo, qué criterio debe imperar en la fase de selección; es decir, qué punto del proceso de integración es el más adecuado para considerar que la palabra en cuestión refleja suficientemente el uso de la lengua por parte de los hablantes y puede admitirse en un diccionario. Azorín Fernández (2015) estudia con detalle y ejemplifica los criterios que, en este sentido, ha utilizado la RAE en el momento de incorporar voces procedentes de otras lenguas en sus diccionarios, desde la edición de Autoridades hasta la recientemente publicada vigesimotercera edición. La actitud de esta institución, como es bien sabido, destaca ( $y$ ha destacado históricamente) por la reticencia a la aceptación de influencias léxicas de otras 
lenguas por lo que es (y ha sido) poco permeable en el momento de permitir la adición de este tipo de lemas. A pesar de que se demuestra un esfuerzo de apertura a la novedad en las últimas ediciones, por su carácter oficial no deja de ser más restrictiva que otras obras lexicográficas menos sujetas al concepto de modelo y más abiertas a lo que se usa y escucha diariamente en contextos cotidianos, según se demostrará en los siguientes apartados.

\subsection{Presencia o ausencia de extranjerismos cotidianos en los diccionarios}

En la actualidad, el punto inicial del proceso de integración es la sincronía contemporánea; es decir, la que hace referencia a las voces extranjeras de reciente uso en la lengua que están presentes o ausentes en los diccionarios. En el momento en que pasan a formar parte de ellos, pueden manifestar (o no) los primeros indicios de adaptación o incluso la propuesta completa, lo que no significa que esté aceptada por quienes las utilizan. Independientemente de que estas palabras estén o no recogidas en las obras lexicográficas, los hablantes no las perciben aún como propias del español puesto que para ello es indispensable la sucesión temporal correspondiente que permita que estos nuevos elementos léxicos queden asentados en la lengua y dejen de reconocerse como foráneos. Dicho de otro modo, es esencial que se cumpla por completo el proceso de integración y el tiempo imprescindible para su culminación no es siempre el mismo en todos los casos (véase \$3.2). 
El adjetivo cotidiano con el que se ha encabezado este apartado no hace referencia exclusiva a palabras de uso común, sino que puede atribuirse también al léxico especializado que, a pesar de ir acompañado de marcas diatécnicas en el contexto lexicográfico, no se emplea exclusivamente por especialistas en la materia, sino que ha pasado a formar parte del lenguaje diario. Sin embargo, por lo general, este tipo de términos no siempre se emplean por toda la población, sino que suelen ser característicos de grupos generacionales concretos, con niveles socioculturales determinados. El componente diastrático es esencial, en tales casos, para facilitar la entrada de extranjerismos.

La ejemplificación de este apartado debe organizarse en diferentes bloques en función de las características que presente cada uno de sus componentes y tomando como base principal, junto con otras obras y ediciones académicas, el DLE 2014, como diccionario normativo, y el CLAVE, como diccionario de uso.

(a) Ausencia en el DLE 2014 y en el CLAVE:

En el contexto contemporáneo, el punto inicial del proceso de integración, según se ha indicado con anterioridad, puede relacionarse con el reciente uso de determinados extranjerismos o, en la mayoría de casos, de un modo más específico, peregrinismos. En ocasiones estas nuevas palabras ni siquiera aparecen en obras lexicográficas, sean normativas o de uso. No resulta extraño, pues, no encontrar en el CLAVE selfie, usado en el compuesto sintagmático palo selfie, porque en la fecha de última edición de este diccionario (2012) ni siquiera existía este utensilio en el contexto espa- 
ñol y quizá tampoco durante el proceso de elaboración del DLE 2014, aunque saliera al mercado dos años más tarde.

Otras voces de distintos campos semánticos que tampoco aparecen en obras lexicográficas podrían ser ironman (deporte), zumba (baile deportivo), big data (informáticatelefonía), talent show (televisión) o, en el contexto coloquial informático, app (acortamiento de applet que sí está en el CLAVE, según se explicitará más adelante). En otros casos, como en indoor y outdoor, solo se halla uno de ellos en el diccionario CLAVE. No deja de ser sorprendente, sin embargo, a pesar de que puedan ser extranjerismos innecesarios o xenismos, porque ambos se aplican a determinados deportes como el ciclismo indoor y el ciclismo outdoor, por ejemplo.

En el contexto comercial español, durante el mes de noviembre - punto de partida para la Navidad-, se estimula, por influencia estadounidense, la compra en fechas concretas después del día de la acción de gracias como ocurre en el Black Friday (descuentos en la mayoría de tiendas, especialmente en grandes almacenes) o en el Cyber Monday (descuentos en compras virtuales). Se han intentado introducir las traducciones Viernes Negro y Cyber lunes; no obstante, siguen prevaleciendo las opciones angloamericanas, tanto desde el punto de vista oral como escrito (contexto periodístico). En Barcelona existe también la shopping night en la que las tiendas se mantienen abiertas desde las ocho de la noche hasta la madrugada. Para la correspondiente denominación, se ha recurrido una vez más al inglés que sigue siendo aún la lengua de mayor influencia y prestigio. 
(b) Ausencia en el DLE 2014 y presencia en el CLAVE: El CLAVE (2012), como diccionario de uso, registra muchos más extranjerismos que el diccionario académico puesto que su objetivo principal, al igual que cualquier obra lexicográfica de estas características, es reflejar el tipo de léxico que se utiliza en la lengua en el periodo correspondiente a su edición. Por lo tanto, no resulta extraño encontrar lemas de diferentes campos semánticos que en el DLE (dos años más tarde) aún no se han incluido. En el cuadro 2, que se presenta a continuación, se ha escogido una muestra de veinte de ellos de diferentes procedencias aunque la predominante, al igual que en el siglo pasado, sigue siendo la inglesa:

\begin{tabular}{|c|c|c|}
\hline CLAVE & SIGNIFICADO & ETIMOLOGÍA \\
\hline applet & $\begin{array}{l}\text { 'aplicación informática que se difunde } \\
\text { a través de la red y se ejecuta en el } \\
\text { navegador de usuario' }\end{array}$ & $<$ ing. applet \\
\hline cool & $\begin{array}{l}\text { 'genial' o 'estilo de música de jazz que } \\
\text { se aleja de la improvisación' }\end{array}$ & $<$ ing. cool \\
\hline loft & $\begin{array}{l}\text { 'tipo de vivienda adaptada de un } \\
\text { almacén o espacio industrial que se } \\
\text { encuentra especialmente en un ático' }\end{array}$ & $<$ ing. loft \\
\hline notebook & $\begin{array}{l}\text { 'ordenador portátil, plegable y de } \\
\text { poco peso' }\end{array}$ & $<$ ing. notebook \\
\hline router & $\begin{array}{l}\text { 'dispositivo informático que permite } \\
\text { el enlace entre distintas redes' }\end{array}$ & $<$ ing. router \\
\hline rottweiler & $\begin{array}{l}\text { 'perro de media estatura, cuerpo } \\
\text { musculoso y pelo negro, corto y duro' }\end{array}$ & $<$ al. Rottweiler \\
\hline showman & 'artista famoso' & $<$ ing. showman \\
\hline celebrity & $\begin{array}{l}\text { 'persona famosa o que goza de } \\
\text { popularidad pública' }\end{array}$ & $<$ ing. celebrity \\
\hline hit & $\begin{array}{l}\text { 'producto de éxito en el mundo del } \\
\text { espectáculo' }\end{array}$ & $<$ ing. hit \\
\hline
\end{tabular}




\begin{tabular}{|c|c|c|}
\hline homeless & $\begin{array}{l}\text { 'persona que vive en la calle y que } \\
\text { suele mantenerse de la mendicidad' }\end{array}$ & $<$ ing. homeless \\
\hline match & $\begin{array}{l}\text { 'en deporte, enfrentamiento de dos } \\
\text { equipos' }\end{array}$ & $<$ ing. match \\
\hline merchandising & $\begin{array}{l}\text { 'en economía, conjunto de } \\
\text { tareas encaminadas a mejorar la } \\
\text { comercialización de un producto' }\end{array}$ & $\begin{array}{l}<\text { ing. } \\
\text { merchandising }\end{array}$ \\
\hline playoff & $\begin{array}{l}\text { 'en algunas competiciones deportivas, } \\
\text { fase final o segunda fase de } \\
\text { desempate' }\end{array}$ & $\begin{array}{l}<\text { ing. playoff I } \\
\text { play-off }\end{array}$ \\
\hline link & $\rightarrow$ hipervínculo & $<$ ing. link \\
\hline tablet & $\rightarrow$ tableta & $<$ ing. tablet \\
\hline avant match & $\rightarrow$ prepartido & $\begin{array}{l}<\text { fr. avant }+ \text { ing. } \\
\text { match }\end{array}$ \\
\hline gigoló & $\begin{array}{l}\text { 'hombre joven que tiene relaciones } \\
\text { sexuales con una mujer de más edad } \\
\text { que lo mantiene' }\end{array}$ & $<$ fr. gigolo \\
\hline back-up & 'en informática, copia de seguridad' & $<$ ing. back up \\
\hline final four & $\begin{array}{l}\text { 'en algunos deportes, fase final de una } \\
\text { competición' }\end{array}$ & $<$ ing. final four \\
\hline top manta & $\begin{array}{l}\text { 'puesto ambulante en el que se venden } \\
\text { copias ilegales de discos compactos } \\
\text { a precios mucho más baratos que los } \\
\text { del disco original' }\end{array}$ & $\begin{array}{l}<\text { ing. top (/ on } \\
\text { blankets })\end{array}$ \\
\hline
\end{tabular}

Cuadro 2. Extranjerismos presentes en el CLAVE y ausentes en el DLE 2014

Al tratarse, como se ha comentado con anterioridad, del punto inicial del proceso de integración, no sorprende que la mayoría de los elementos léxicos incorporados al español mantengan su forma extranjera. Esta característica refleja que los hablantes, a pesar de integrar estas palabras en sus conversaciones cotidianas, sean o no específicas de temas concretos, son conscientes de que no se trata de voces au- 
tóctonas del español y, en el ámbito escrito, deban indicarlo (cursiva u otra distinción gráfica). Aun así, pueden observarse diferencias entre ellas no solo desde el punto de vista de la percepción de quienes las usan, sino de las características que manifiestan algunas en su formación, en el grado de adaptación, si se les ha aplicado, o en el tipo de consideración que reciben por parte del diccionario de uso dentro del contexto español.

El CLAVE indica explícitamente que las palabras cool, loft, rottweiler, showman y las contextualizadas en el terreno informático (notebook, router y applet) son extranjerismos, aunque no a todas se les puede aplicar el término peregrinismo, como sucede en cool, en el sentido de 'genial', o en showman, por ejemplo. A excepción de cool, que es adjetivo invariable, se da por supuesto que la formación del plural del resto (todos sustantivos) se realiza según las reglas propias del español (adición de -s). ${ }^{6}$ En cuanto al género, solo showman puede ser variable; no obstante, por su condición de compuesto, para la forma femenina se adopta un nuevo extranjerismo, cuya diferencia se observa en la segunda palabra donde aparece el heterónimo correspondiente a man. Desde el punto de vista gráfico-fonético, se caracteriza por una degeminación consonántica $(w w \rightarrow w)$ : showoman.

En el caso de otros extranjerismos ejemplificados en el cuadro 2, se indica que su uso es innecesario porque el

\footnotetext{
${ }^{6}$ Rottweiler puede utilizarse como adjetivo invariable o como sustantivo. En esta segunda opción, su plural debería ser en -es por la terminación - $r$, según la NGLE $\$ 3.2 \mathrm{k}$, aunque se trate de un extranjerismo (NGLE $\$ 3.4 \mathrm{~g}$ ); sin embargo, su uso real es mediante -s (cf. CREA y CORPES XXI, donde solo se han encontrado ejemplos en -s y ninguno en -es, ni en el español peninsular ni en el de zonas hispanoamericanas).
} 
propio español ya posee equivalentes para ellos. Se pueden considerar, por lo tanto, xenismos. Se trata de celebrity, hit, homeless, match, merchandising y playoff, que podrían sustituirse por celebridad o famoso, éxito, sin techo, partido, promoción comercial y fase final, respectivamente. Todos ellos, sin embargo, aparecen documentados en el CORPES XXI en las diferentes zonas de habla hispana. En el contexto deportivo, podría añadirse que se utilizan como sinónimos match y partido, aunque este último, hasta el momento, sigue siendo el más frecuente. Entre los ejemplos citados, merchandising resulta especialmente interesante porque es sinónimo de otro anglicismo, marketing, incluido tanto en el CLAVE como en el DLE 2014. Mientras que este diccionario ofrece información completa para merchandising, marketing remite, en ambos, al término especializado mercadotecnia, propio del español, y es en su artículo lexicográfico donde pueden hallarse los datos que interesan. A nuestro modo de ver, sería oportuno, junto a la voz especializada, añadir el compuesto sintagmático usado con mayor frecuencia en el lenguaje común (promoción comercial) que el CLAVE solo reserva para merchandising. Si se sigue con el recurso lexicográfico de las remisiones, en el cuadro 2 podemos encontrar tres ejemplos: link, tablet y el extranjerismo híbrido avant match, formación composicional que se adopta simultáneamente del francés (avant) y del inglés (match). Las remisiones son, respectivamente, hipervínculo, tableta y prepartido, este último derivado por prefijación que solo está registrado en el CLAVE con el significado de 'tiempo anterior al comienzo de un partido'. Las diferencias entre ellas se basan en que la primera y la última solo poseen un 
significado, coincidente con el de las respectivas lenguas de importación, mientras que tableta, en el sentido informático, es un préstamo semántico, por lo tanto, se trata, en esta ocasión, de la adición de una acepción nueva a una voz que ya formaba parte del español.

Del mismo modo que en algunos casos, aunque se trate de extranjerismos de reciente incorporación o inadmisibles desde el punto de vista normativo, se especifican adaptaciones fonéticas, en otras ocasiones podemos encontrar, además, alguna adaptación gráfica, como en el caso de gigoló, al que se añade la tilde para indicar la pronunciación aguda del francés, o back-up, al que se agrega el guion para especificar que up forma parte del significante de este anglicismo. Para este segundo extranjerismo se especifica que "su uso es innecesario" (CLAVE, s.v. back-up), pero no se propone ninguna palabra para utilizar en su lugar, aun así, deducimos que es interpretable a partir de la definición (copia de seguridad). Según se ha indicado con anterioridad, los significantes de las formas léxicas no se restringen a una única palabra, sino que puede tratarse de compuestos sintagmáticos. Este es el caso de final four o top manta, de formación distinta entre sí. En el primer ejemplo, se han incorporado del inglés los dos elementos compositivos. Como ha ocurrido en otras ocasiones, además de indicar su adaptación fonética, se especifica que puede prescindirse de su uso, pero no se ofrece ningún sustituto. Si se recurre a la definición, debería ser fase final. Top manta, en cambio, es una formación distinta que no se presenta como innecesaria ya que designa un concepto desconocido con anterioridad. Se recurre al inglés para la primera parte del compuesto, mien- 
tras que para la segunda se aprovecha una voz del propio español. Lo que llama especialmente la atención es que no existe en inglés un compuesto similar. Para indicar lo mismo en esta lengua se utiliza on blankets. Esta diferenciación corrobora la concepción de una determinada lengua como modelo en el momento de formar nuevas palabras o expresiones que ni siquiera existen en el idioma que las transmite (cf. footing, por ejemplo, que, a diferencia de lo que parece, se trata de un galicismo $y$, contrariamente a lo que se esperaría, en inglés no posee el sentido deportivo con el que se emplea en francés y en español, sino que se interpreta principalmente como 'punto de apoyo' o 'asidero').

La opción inversa a la que se ha analizado en este apartado, es decir, nuevas entradas del DLE 2014 y ausencia en el CLAVE, no ocurre con demasiada frecuencia, aunque es insólito que pase para dron 'aeronave no tripulada', procedente del inglés drone. Se trata, sin lugar a dudas, de un caso particular puesto que más que extrañar su ausencia en el diccionario de uso, sorprende que ya esté incluido en la última edición del DLE por su reciente empleo en español.

(c) Nuevas entradas en el DLE 2014 y presencia en el CLAVE:

Siempre que aparece una nueva edición lexicográfica de un Diccionario de la lengua española de la RAE se observa que no solo se han producido enmiendas respecto al contenido de la anterior, sino adiciones de otros lemas y significados. En esta ocasión, en el cuadro 3 se ha recogido una muestra de nuevas entradas del DLE 2014 que están también presentes - y no resulta extraño- en el CLAVE. El criterio de nueva aceptación de la RAE se produce, por lo general, cuando 
las palabras poseen una historia, aunque reciente, bastante significativa en el uso de la lengua por parte de los hablantes, lo que puede ser indicativo del desarrollo del proceso de integración o incluso, en algunos casos, de su proximidad a la culminación, aunque se hayan incluido por primera vez en la última edición del diccionario académico.

\begin{tabular}{|c|c|c|c|}
\hline DLE & CLAVE & SIGNIFICADO & ETIMOLOGÍA \\
\hline $\operatorname{pin}^{2}$ & pin & $\begin{array}{l}\text { 'contraseña alfanumérica de } \\
\text { algunos aparatos electrónicos' }\end{array}$ & $\begin{array}{l}<\text { ingl. pin } \\
\text { (acrón.) }\end{array}$ \\
\hline baguette & baguette & $\begin{array}{l}\text { 'barra de pan estrecha y } \\
\text { alargada' }\end{array}$ & $<$ fr. baguette \\
\hline blog & $b \log$ & $\begin{array}{l}\text { 'sitio web en el que se escriben } \\
\text { opiniones sobre algún tema } \\
\text { y que suele actualizarse con } \\
\text { frecuencia' }\end{array}$ & $<$ ingl. blog \\
\hline stop & stop & $\begin{array}{l}\text { 'señal de tráfico que indica a los } \\
\text { conductores la obligación de } \\
\text { detenerse' }\end{array}$ & $<$ ingl. stop \\
\hline playboy & playboy & $\begin{array}{l}\text { 'hombre, generalmente rico } \\
\text { y atractivo, de vida ociosa y } \\
\text { sexualmente promiscua' }\end{array}$ & $<$ ingl. playboy \\
\hline jet lag & jet lag & $\begin{array}{l}\text { 'trastorno o malestar producido } \\
\text { por un viaje en avión con } \\
\text { cambios horarios considerables' }\end{array}$ & $<$ ingl. jet lag \\
\hline wifi & $w i-f i$ & $\begin{array}{l}\text { 'sistema de conexión } \\
\text { inalámbrica, dentro de un área } \\
\text { determinada, que posibilita } \\
\text { el acceso a internet entre } \\
\text { dispositivos electrónicos' }\end{array}$ & $\begin{array}{l}<\text { ingl. WI-FI } \\
\text { (marca reg.) }\end{array}$ \\
\hline sudoku & sudoku & $\begin{array}{l}\text { 'pasatiempo que consiste en } \\
\text { completar con números del } 1 \text { al } \\
9 \text { las casillas de una cuadrícula } \\
\text { respetando determinadas reglas' }\end{array}$ & < jap. sūdoku \\
\hline
\end{tabular}




\begin{tabular}{|c|c|c|c|}
\hline sushi & sushi & $\begin{array}{l}\text { 'comida de origen japonés que } \\
\text { suele hacerse con arroz y trozos } \\
\text { de pescado crudo envuelto en } \\
\text { algas' }\end{array}$ & $<$ jap. sushi \\
\hline$m a n g a^{3}$ & manga & 'cómic de origen japonés' & $<$ jap. manga \\
\hline chucrut & chucrut & $\begin{array}{l}\text { 'col blanca fermentada que se } \\
\text { suele tomar acompañando a } \\
\text { otros alimentos' }\end{array}$ & $<$ fr. choucroute \\
\hline $\begin{array}{l}\text { friki } \\
\text { (tb. friqui) }\end{array}$ & friki & 'extravagante, raro o excéntrico' & $<$ ingl. freaky \\
\hline tuit & tweet & $\begin{array}{l}\text { 'mensaje digital que se envía a } \\
\text { través de la red social Twitter } \\
\text { y que no puede rebasar un } \\
\text { número limitado de caracteres' }\end{array}$ & $<$ ingl. tweet \\
\hline yihad & yihad & $\begin{array}{l}\text { 'guerra santa de los } \\
\text { musulmanes' }\end{array}$ & < árabe ǧihād \\
\hline párking & parking & $\rightarrow$ aparcamiento & $<$ ingl. parking \\
\hline spanglish & espanglish & $\begin{array}{l}\rightarrow \text { espanglish }(\mathrm{DLE}) / \rightarrow \\
\text { spanglish }(\mathrm{CLAVE})\end{array}$ & $<$ ingl. spanglish \\
\hline spam & spam & $\begin{array}{l}\rightarrow \text { correo basura (DLE) / } \\
\text { 'correo electrónico enviado } \\
\text { masivamente, generalmente } \\
\text { de contenido publicitario' } \\
\text { (CLAVE) }\end{array}$ & $<$ ingl. spam \\
\hline spa & spa & $\begin{array}{l}\text { 'establecimiento que ofrece } \\
\text { tratamientos, terapias o } \\
\text { sistemas de relajación, } \\
\text { utilizando como base principal } \\
\text { el agua, generalmente corriente, } \\
\text { no medicinal' (DLE) / } \rightarrow \\
\text { balneario (CLAVE) }\end{array}$ & $<$ ingl. spa \\
\hline
\end{tabular}

Cuadro 3. Nuevos extranjerismos en el DLE 2014 presentes en el CLAVE

Al igual que ocurre con las voces incorporadas solo en el CLAVE que se han incluido en el subapartado anterior, hay un número de elementos léxicos que no manifiesta (o 
prácticamente no manifiesta) ningún tipo de adaptación gráfica (aunque sí fonética en algunos casos): es evidente que uno de ellos no precisa cambios por su equivalencia a las condiciones lingüísticas del español (pin, acrónimo de personal identification number), mientras que el resto podría necesitarlos, aunque sería difícil que se produjeran si se tiene en cuenta el uso bastante establecido que la mayoría ya posee con la forma originaria (baguette, blog, ${ }^{7}$ stop, playboy, jet lag, wifi, sudoku y sushi). La Academia permite escribir también el compuesto playboy con los elementos formativos separados (play boy). Esto significa que aparece también como lema en este diccionario y en él se remite al significante preferente (playboy). Para pin, el CLAVE (s.v. pin) desaconseja el uso del "plural anglicista pins" (en lugar de pines), al igual que el DPD para su homónimo con el significado de insignia o adorno pequeño que se lleva prendido en la ropa'; sin embargo, la forma sin -e- sigue siendo la más utilizada (cf. CREA y CORPES XXI, donde solo se hallan documentaciones con la acepción que acaba de indicarse y no con la más reciente). Desde el punto de vista semántico, el DPD, al igual que el CLAVE, proponía para jet lag una equivalencia española (desfase horario), información que el DLE 2014 ha desestimado tal vez por no poseer exactamente el mismo significado. El CLAVE, a diferencia

\footnotetext{
${ }^{7}$ Prat Sabater y Sierra Infante (2011: 158) se sorprendieron de que tanto blog como los derivados bloguero y blogosfera no aparecieran en diccionarios escolares, puesto que en esa fecha ya eran muy populares entre los jóvenes y más aún en el contexto de la educación. Su ausencia era todavía evidente también en diccionarios generales, aunque desde unos años antes ya se hacía referencia a blog en el DPD (s.v. bitácora).
} 
del diccionario académico, suele agregar con mayor asiduidad equivalencias españolas para los extranjerismos que las poseen; sin embargo, algunas de ellas pueden haber perdido su frecuencia de uso en el contexto coloquial ante las nuevas palabras recibidas de otras lenguas: blog-bitácora y playboyconquistador/donjuán. En este grupo de ejemplos, junto con otro que se comentará a continuación, empieza a observarse la incipiente influencia de lenguas orientales, representada en este caso por el japonés.

Otro conjunto destacado de palabras se presenta con adaptaciones gráficas completas según la normativa del español (friqui, $m a n g a^{3}$ ) o próximas a ella y representativas de la correspondiente pronunciación extranjera (chucrut, tuit $^{8}$ y yihad). Asimismo, pueden comprobarse las diferencias de adaptación entre DLE 2014 y CLAVE en los ejemplos de tuit/tweet, wifi/wi-fi y friqui/friki, aunque, en este último caso, la RAE sigue prefiriendo la forma extranjera que, en realidad, es la más común entre los hablantes. En cuanto a las dos primeras, debe destacarse la diferencia de uso mayoritario entre el español peninsular (tuit y wifi) y el hispanoamericano (tweet y wi-fi), según se constata en el CORPES XXI. Cabe destacar que para wi-fi, el CLAVE también indica la forma sin guion aunque no la incluye como lema.

El último grupo del cuadro 3 es el destinado a remisiones, por lo tanto está formado por xenismos o palabras innecesarias por ya disponer de equivalencias autóctonas del español. Tanto el DLE 2014 como el CLAVE proponen apar-

\footnotetext{
${ }^{8}$ Prat Sabater y Sierra Infante (2011: 158) ya comentaban la necesidad de que en breve tanto esta palabra como su derivado tuitear, formaran parte de los diccionarios por su creciente uso en los medios de comunicación.
} 
camiento en lugar de parking. La única diferencia entre ambos es que solo el académico muestra indicios de adaptación de esta voz mediante la tilde (párking). El CLAVE mantiene la forma original inglesa que, en realidad, es la más utilizada, aunque aún menos que aparcamiento (cf. CORPES XXI). En el caso de spanglish/espanglish, no existe acuerdo entre las dos obras lexicográficas en cuanto a preferencia. Ambas incluyen las dos formas, aunque al igual que en el ejemplo anterior, para el CLAVE prevalece la que coincide con la forma inglesa que, en realidad, es la más empleada por escrito en todos los ámbitos de habla hispánica (cf. CORPES XXI). Tampoco hay coincidencia por lo que corresponde a remisiones en las dos últimas palabras (spam y spa): el DLE 2014 propone el empleo de correo basura para spam y el CLAVE, balneario para spa. Cuando no se ofrece remisión, se incluye directamente el significado del término, lo que es indicativo de su aceptación como palabra propia del español, a pesar de la no coincidencia entre las fuentes. Tanto para spam como para spa, en el CORPES XXI se encuentran alrededor de seiscientas documentaciones en las diferentes zonas de habla hispana desde 2001 hasta 2014. Es indiscutible que, por el momento, ambos elementos léxicos conviven con las respectivas opciones españolas a las que se ha remitido. El proceso de integración, por lo tanto, no ha llegado a su fin, aunque parece ser que el uso de correo basura es inferior al de spam, mientras que el de balneario es aún superior al de spa (cf. CORPES XXI). La lucha entre ambas alternativas puede llegar en los dos casos a la sustitución absoluta de una de las dos palabras o al mantenimiento de ambas durante un periodo más extenso o indefinido. 
Los ejemplos recogidos en este epígrafe, ausentes o presentes por primera vez en las obras lexicográficas escogidas son una muestra de extranjerismos desde el punto de vista de la concepción de los hablantes. La razón principal es que siguen percibiendo su origen foráneo; sin embargo, desde esta perspectiva, no todas están en igualdad de condiciones. Mientras que la mayoría se encuentran en los inicios del proceso de integración, otras, por su uso reiterado, están más cerca de su culminación o en una etapa más avanzada, como match, pin o baguette.

\subsection{Incorporación u omisión de cambios en el paso de extranjerismo a préstamo léxico a lo largo de la historia lexicográfica académica del español}

Es posible, según se ha comentado con anterioridad, que los nuevos lemas de cualquiera de las ediciones académicas sean representativos del inicio o del final del proceso de integración. Los que se hallan en la primera o las primeras ediciones recogen el vocabulario de la lengua del momento y, por lo tanto, muchas de las palabras que incluyen son ya préstamos léxicos y ni siquiera se intuye que se hayan percibido como extranjerismos en épocas anteriores. Cuanta más historia posee la lexicografía académica, más novedad se intuye en las nuevas entradas a pesar de la actitud conservadora por la que históricamente se ha caracterizado esta institución. En los siguientes subapartados, se ilustrará cómo puede advertirse desde el punto de vista lexicográfico el paso de extranjerismo a préstamo léxico, siempre y cuando el proceso de adaptación no haya culmi- 
nado en el momento de la inclusión de la palabra en el diccionario.

(a) Muestra de primeras documentaciones lexicográficas académicas con mantenimiento de la forma gráfica extranjera:

En el cuadro 4 que se presentará a continuación se evidenciará una evolución histórica del cambio léxico. Los ejemplos de las ediciones de los siglos XVIII y XIX ya parecen considerarse préstamos léxicos y, por lo tanto, en etapas anteriores, han experimentado el proceso de integración, equivalente a su progresiva aceptación por los hablantes de la época. Las del siglo $\mathrm{xx}$, a pesar de resultar muy familiares en el uso común de la lengua, no han podido desprenderse completamente de su condición de extranjerismo, especialmente en el momento de expresarlas por escrito.

\begin{tabular}{|c|c|c|}
\hline ed. DRAE & LEMA & ETIMOLOGÍA \\
\hline $1780\left(1^{\mathrm{a}}\right)$ & fusil & $<$ fr. fusil \\
\hline $1817\left(5^{\mathrm{a}}\right)$ & piano o pianoforte & $<$ it. pianoforte \\
\hline $1869\left(11^{\mathrm{a}}\right)$ & complot & $<$ fr. complot \\
\hline $1884\left(12^{\mathrm{a}}\right)$ & \multicolumn{2}{|l|}{ piano } \\
\hline \multirow{2}{*}{$1984\left(20^{\mathrm{a}}\right)$} & iceberg & $<$ ingl. iceberg \\
\hline & pizza & $<$ it. pizza \\
\hline $1992\left(21^{\mathrm{a}}\right)$ & clip $^{9}$ & $<$ ingl. clip \\
\hline \multirow{2}{*}{$2001\left(22^{\mathrm{a}}\right)$} & $\operatorname{clip}^{2}(\rightarrow$ videoclip $)$ & $<$ ingl. videoclip \\
\hline & roulotte & $<$ fr. roulotte \\
\hline $2014\left(23^{a}\right)$ & \multicolumn{2}{|c|}{ fusil, complot, piano, iceberg, pizza, clip $p^{1}$ y clip ${ }^{2}$, roulotte } \\
\hline
\end{tabular}

Cuadro 4. Extranjerismo > préstamo léxico (sin adaptación gráfica)

\footnotetext{
${ }^{9}$ Utensilio hecho con un trozo de alambre, u otro material, doblado sobre sí mismo, que sirve para sujetar papeles (DLE 2014, s.v. clip $^{1}$ ).
} 
Dentro de este grupo de elementos léxicos del cuadro 4, el que muestra mayor alternancia formal es piano a pesar de ser fiel al étimo italiano. La Academia ya especifica dos formas posibles en el momento en que lo acepta para formar parte de su quinta edición: la idéntica al étimo italiano y la que solo mantiene la primera parte del compuesto que es la que ha llegado hasta la actualidad y así se indica en los diccionarios académicos a partir de 1884 . No resulta extraño, en esta ocasión, que se esperara hasta finales del siglo XIX para tomar una decisión al respecto puesto que a lo largo de esta centuria no solo se hallan documentados pianoforte y piano, sino también forte-piano (cf. CORDE, $\mathrm{CDH}$ y DECH, s.v. llano). Fusil y complot, en cambio, están documentados con anterioridad sin variación en la forma porque coinciden exactamente con el étimo francés: fusil, invención de finales del XVII, documentado a principios del XVIII por las mismas fuentes; y complot, con terminación - $t$ impropia del español en esta posición, documentado a principios del siglo Xviı por el CORDE y el CDH. Entre el resto de ejemplos que, de entrada, pueden parecer más recientes por estar incorporados en la lexicografía académica a finales del siglo $\mathrm{xx}$, debe destacase iceberg, documentado a finales del siglo xix (cf. CORDE y CDH) y suficientemente importante por el suceso que ocurrió con el Titanic en el año 1912. Sorprende no hallarlo en ediciones anteriores ante la ausencia de un equivalente español en una sola palabra. Pizza, el par de homónimos con la forma clip y roulotte, de campos semánticos distintos, tampoco han manifestado ningún tipo de modificación, pero están perfectamente integrados en el vocabulario de los hablantes. 
El único elemento léxico, en este caso, que tiene competencia española es roulotte que, en las dos ediciones en que aparece remite a caravana. Sin embargo, el CORPES XXI documenta su vitalidad entre 2001 y 2010, aunque el uso de caravana sea significativamente mayor. Este galicismo ya se había incluido en los manuales académicos de 1985 y 1989 con la misma forma; sin embargo, desde entonces no vuelve a aparecer en ninguna de sus obras hasta la publicación de la vigesimosegunda edición.

(b) Muestra de primeras documentaciones lexicográficas académicas con adaptación completa de la forma gráfica extranjera

En el momento en que se localizan en alguna edición adaptaciones de étimo foráneo, es posible que con anterioridad a la historia lexicográfica académica se halle convivencia entre diferentes variantes, aunque no ocurre en todos los casos y, si sucede, no siempre se encuentran todas documentadas. Este periodo de convivencia es el que coincide con el desarrollo del proceso de integración. Cuando en obras lexicográficas se ofrece, sin vacilación, una única opción, se presupone que, en función de la mayor o menor proximidad al presente inmediato, puede haber culminado o está a punto de culminar el proceso. Los hablantes, en cada caso, y en el momento cronológico correspondiente, siempre tienen que haber mostrado conformidad por ser los usuarios de la lengua. En el cuadro 5 se presenta una muestra de ejemplos que cumplen estas características. 


\begin{tabular}{|l|c|l|}
\hline ed. DRAE & LEMA & \multicolumn{1}{|c|}{ ETIMOLOGÍA } \\
\hline $1726($ Aut. $)$ & arlequín & $<$ it. arlecchino \\
\hline $1884\left(12^{\mathrm{a}}\right)$ & acuarela & $<$ it. acquarella \\
\hline $1936\left(16^{\mathrm{a}}\right)$ & glaciar & $<$ fr. glacier \\
\hline \multirow{2}{*}{$1970\left(19^{\mathrm{a}}\right)$} & esmoquin & $<$ ingl. smoking \\
\cline { 2 - 3 } & voleibol & $<$ ingl. volleyball \\
\hline \multirow{2}{*}{$1992\left(21^{\mathrm{a}}\right)$} & eslogan & $<$ ingl. slogan \\
\hline $2014\left(23^{\mathrm{a}}\right)$ & arlequín, acuarela, glaciar, esmoquin, voleibol, eslogan \\
\hline
\end{tabular}

Cuadro 5. Extranjerismo $>$ préstamo léxico

(adaptación gráfica completa)

La forma arlequín, documentada por primera vez entre los siglos XVI y XVII (cf. CORDE, CDH y DECH, s.v. arlequín), ha presentado, a lo largo de su historia, diferentes variantes, aunque no todas indicativas de la misma procedencia etimológica. Corominas y Pascual destacan el uso de arnequín o las formas hispanoamericanas arrenquín, arrinquín, arriquín, o incluso el canario arranclín que, en última instancia, según los citados etimólogos, tendrían todas, por su aspecto gráfico, una procedencia francesa (DECH, s.v. arlequín). En el DA se encuentra arrenquín, pero con significados totalmente diferentes. En cualquier caso, es el italianismo el que ha triunfado y culminado el proceso de integración. En cuanto a glaciar, el CORDE y el CDH documentan con anterioridad la forma francesa glacier $\left(2^{\mathrm{a}}\right.$ mitad del siglo XIX); sin embargo, pronto se sustituye por la que ha pervivido hasta la actualidad. Para acuarela, en cambio, no se dispone de variantes documentadas y se ha utilizado siempre tal y como consta en la edición de 1884 . 
La forma esmoquin se integró totalmente adaptada en la decimonovena edición (casi un siglo más tarde) y desde entonces no ha manifestado cambios lexicográficos aunque en diferentes manuales (1927 y 1950) se había incluido sin ningún tipo de modificación respecto al étimo inglés (smoking). Voleibol entra también completamente adaptado en la edición de 1970 y se mantiene así hasta la actualidad, aunque en el DLE 2014 se indica la aceptación de la forma con cambio de acentuación (vóleibol), propia de zonas americanas como Chile, México, Perú y Uruguay. El DA añade que esta variante con cambio de tonicidad también se utiliza en Bolivia. Eslogan, en cambio, convive con la forma sin adaptar (slogan). El CORPES XXI confirma significativamente el mayor uso de la adaptación respecto a la forma inglesa, por lo tanto, si aún no ha culminado el proceso de integración, debe de estar a punto. No puede pasar desapercibido, sin embargo, el detalle de que la forma inglesa se utiliza más en zonas hispanoamericanas y la española en la Península.

(c) Muestra de documentaciones académicas con o sin vacilación en la adaptación de la forma gráfica extranjera En ocasiones es posible que, cuando se registra un extranjerismo en el diccionario sin adaptación, en sucesivas ediciones se muestre vacilación en cuál debe ser la forma definitiva, lo que demuestra que la palabra se halla en pleno desarrollo del proceso de integración. Puede ocurrir también que ni siquiera quede resuelto en la última edición, según podrá observarse en el cuadro 6 . 


\begin{tabular}{|c|c|c|}
\hline ed. DRAE & LEMA & ETIMOLOGÍA \\
\hline \multirow{2}{*}{$1925\left(15^{\mathrm{a}}\right)$} & folklore & $<$ ingl. folklore \\
\hline & restaurante & $<$ fr. restaurant \\
\hline \multirow{3}{*}{$1936\left(16^{\mathrm{a}}\right)$} & chófer & $<$ fr. chauffeur \\
\hline & futbol & $<$ ingl. football \\
\hline & chalet & $<$ fr. chalet \\
\hline \multirow{3}{*}{$1956\left(18^{a}\right)$} & \multicolumn{2}{|l|}{ chófer [chofer] } \\
\hline & \multicolumn{2}{|l|}{ fútbol [futbol] } \\
\hline & \multicolumn{2}{|l|}{ chalet $(\rightarrow$ chalé $)$} \\
\hline \multirow{5}{*}{$1970\left(19^{\mathrm{a}}\right)$} & criquet & $<$ ingl. cricket \\
\hline & $y a z$ & $<$ ingl. jazz \\
\hline & \multicolumn{2}{|l|}{ folclor $(\rightarrow$ folklore $) /$ folclore $(\rightarrow$ folklore $)$} \\
\hline & \multicolumn{2}{|l|}{ fútbol o futbol } \\
\hline & \multicolumn{2}{|l|}{ chófer o chofer } \\
\hline \multirow{2}{*}{$1984\left(20^{\mathrm{a}}\right)$} & \multicolumn{2}{|l|}{ folclore $(\rightarrow$ folclor $)$} \\
\hline & \multicolumn{2}{|l|}{ restorán $(\rightarrow$ restaurante $)$} \\
\hline \multirow{2}{*}{$1992\left(21^{\mathrm{a}}\right)$} & bádminton o badminton $(\rightarrow$ volante $)$ & $<$ ingl. badminton \\
\hline & \multicolumn{2}{|l|}{ Omisión de criquet. } \\
\hline \multirow{5}{*}{$2001\left(22^{\mathrm{a}}\right)$} & topless o top-less & $<$ ingl. topless \\
\hline & \multicolumn{2}{|l|}{ folclor $(\rightarrow$ folclore $)$} \\
\hline & \multicolumn{2}{|l|}{ cricket } \\
\hline & \multicolumn{2}{|l|}{ jazz } \\
\hline & \multicolumn{2}{|l|}{ bádminton ( $\rightarrow$ volante) } \\
\hline \multirow{9}{*}{$2014\left(23^{a}\right)$} & \multicolumn{2}{|c|}{ folklor $(\rightarrow$ folclor $) /$ folclor $(\rightarrow$ folclore $) / /$ folklore $(\rightarrow$ folclore $)$} \\
\hline & \multicolumn{2}{|c|}{ restorán $(\rightarrow$ restaurante $)$} \\
\hline & \multicolumn{2}{|l|}{ chófer $(\rightarrow$ chofer $)$} \\
\hline & \multicolumn{2}{|l|}{ futbol $(\rightarrow$ fútbol $)$} \\
\hline & \multicolumn{2}{|l|}{ chalet $(\rightarrow$ chalé $)$} \\
\hline & \multicolumn{2}{|l|}{ cricket $(\rightarrow$ críquet $)$} \\
\hline & \multicolumn{2}{|l|}{ jazz } \\
\hline & \multicolumn{2}{|l|}{ bádminton [volante $\rightarrow$ bádminton] } \\
\hline & \multicolumn{2}{|l|}{ toples } \\
\hline
\end{tabular}

Cuadro 6. Extranjerismo > préstamo léxico (vacilación en la adaptación) 
Según queda documentado desde el punto de vista lexicográfico, folklore se introduce sin adaptación en la edición de 1925. Así se mantiene hasta la de 1970 donde, aparte de seguir considerándose como preferible, convive con diferentes propuestas de adaptación como folclor o folclore. Se omite la forma sin adaptación a partir de 1984; sin embargo, existe discrepancia sobre cuál de las dos restantes es la más extendida: folclor en esta y la siguiente edición, y folclore en la de 2001. En el DLE 2014 sigue siendo esta última la preferente, aunque vuelve a introducirse folklore e incluso una que no había aparecido en ninguna edición: folklor. La justificación de esta discrepancia debe buscarse en el uso real de la lengua. Si se consulta el CORPES XXI, podrá observarse que excepto folklor, exclusiva de Hispanoamérica, las demás se encuentran documentadas en las diferentes zonas de habla hispana, aunque existe un mayor predominio de las adaptadas en el español peninsular. Es evidente, pues, que la sucesión temporal imprescindible para llegar al fin del proceso de integración aún no ha terminado.

El resto de ejemplos son menos complejos. Se vacila, en esta ocasión, entre pares de variantes. A las formas iniciales de chófer y fútbol, propias del español peninsular, se les añaden las formas agudas (chofer y futbol), prácticamente exclusivas de Hispanoamérica (cf. CORPES XXI y DA, s.v. chofer y futbol). Algo similar ocurre con restaurante-restorán. Independientemente de que esta última, similar a la pronunciación francesa, se documente con exclusividad en Hispanoamérica, restaurante, con -e paragógica, se halla en todas las zonas de habla hispana y es la más común entre los hablantes (cf. CORPES XXI). Chalet es otro de los gali- 
cismos incluidos en el cuadro 6 y documentado en la edición de 1936. Desde el punto de vista lexicográfico, ya pasa a adaptarse completamente al español a partir de 1956 (chalé), aun así, el corpus citado posee muchas más documentaciones de la forma con - $t$ entre los años 2001 y 2012, lo que demuestra que los hablantes siguen prefiriendo la forma original y por esta razón ha vuelto a tomarse en consideración en el DLE 2014. El caso de jazz es bastante excepcional. Se introduce por primera vez en 1970 la forma yaz, inusual a lo largo de toda la historia de esta palabra (solo se han localizado muy pocas documentaciones en el CREA) hasta que en el año 2001 se sustituye por la forma inglesa (jazz) que, en realidad, es la que ha prevalecido siempre. En el caso de críquet ocurre algo similar, aunque el punto de partida y el final están formados por distintas formas adaptadas:

criquet $(1970-1884) \rightarrow$ omisión (1992) $\rightarrow$ cricket $(2001) \rightarrow$ cricket y críquet (2014)

La forma preferente del DLE 2014 es críquet; sin embargo, una vez más el CORPES XXI sigue demostrando que el uso de la forma inglesa es superior al de la variante adaptada.

Para otras importaciones ya se ofrecen directamente dos opciones: original y adaptada (bádminton o badminton) y original junto con otra propuesta con alguna variación (topless o top-less). En el primer caso se remite a volante hasta la última edición, donde la remisión se produce a la inversa: el lema volante remite a bádminton, forma adaptada que ha triunfado. En el segundo caso, el DLE 2014 propone una opción con más afinidad a las características del español: to- 
ples; no obstante, la más documentada sigue siendo topless (cf. CORPES XXI).

En estos últimos grupos de ejemplificación, puede observarse que la discrepancia entre Academia y hablantes o incluso variedad dialectal se constata con la vacilación lexicográfica. Es evidente, por lo tanto, que el proceso de integración tampoco ha culminado.

No en todos los casos en que las ediciones del DRAE proponen adaptaciones se muestra tanta vacilación como los que acaban de comentarse puesto que, a veces, con una propuesta es suficiente. Podría ejemplificarse con scooter (2001) $\rightarrow$ escúter (2014), y paddle (2001) $\rightarrow$ pádel (2014). Sin lugar a dudas, esta última palabra es la que en un tiempo más breve ha superado el proceso de integración, al menos en el territorio peninsular. Aunque haga referencia a un deporte relativamente nuevo, nadie discute la utilización de pádel, que se ha desprendido completamente de su condición inglesa.

No puede cerrarse este apartado sin destacar las dificultades con las que se encuentran los lexicógrafos en el momento de elaborar un diccionario: por un lado, deben convivir con la presión general de la necesidad de incluir todas las voces de la lengua y, por otro, con la responsabilidad de garantizar que su perduración en la lengua es viable tal y como deciden proponerla. Según manifestaba Álvarez de Miranda, para los elementos léxicos incorporados de otras lenguas "es bueno que la RAE proponga una solución con celeridad. Después hay que cruzar los dedos para que la gente la acepte. No siempre se logra. Se intentó con «balompié» para «fútbol», pero no se consiguió. En cambio, sí caló «baloncesto», una españolización de «basketball». ¿ Por 
qué? No hay respuesta. Las palabras se extienden como una mancha por la colectividad social y no siguen patrones fijos" (Ors, 2014). Con estas reflexiones se confirma que no se puede predecir el cambio lingüístico, en general, ni el léxico, en particular.

\section{Conclusión}

En el contexto del préstamo integral, extranjerismo y préstamo léxico son dos términos fundamentales relacionados, como se ha demostrado, con la sincronía y la diacronía, respectivamente. El paso de uno a otro implica que se cumpla el proceso de integración que no depende exclusivamente de si se produce o no adaptación léxica en la lengua receptora, sino de la progresiva pérdida de conciencia por parte de los hablantes de la procedencia extranjera de las voces que utilizan. El punto de partida y el término de este proceso pueden situarse en cualquier periodo histórico. La duración es impredecible, aunque a partir de la documentación escrita puede deducirse para las voces que ya se consideran préstamos léxicos.

Después de analizar la presencia lexicográfica de algunas de estas palabras, puede concluirse que cuanto más lejanas son las primeras documentaciones en los diccionarios, menos percepción de extranjerismo posee el hablante (arlequín, piano, complot o glaciar). Esto supone, por lo tanto, la culminación del proceso de integración, lo que conlleva que estas voces se consideren préstamos léxicos. En cambio, cuanto más recientes son, con adaptación formal (esmoquin, 
voleibol o eslogan) o sin ella (baguette, jet lag o blog) o con vacilación lexicográfica entre variantes (chofer/chófer, chalél chalet o críquet/cricket), suele aumentar la percepción de extranjerismo. Esto hace presuponer que se encuentran entre el estadio inicial del proceso de integración y el punto más avanzado del mismo; es decir, se hallan en la fase del paso de extranjerismo a préstamo léxico. $\mathrm{Si}$, además, las palabras importadas no aparecen registradas en ninguna obra lexicográfica (ironman, zumba o selfie) o en solo una de ellas, sea de uso (applet, celebrity o avant match) o definitoria (dron), es muy probable que se encuentren en el punto sincrónico que permite iniciar el proceso y, por lo tanto, aún se consideran sin ninguna duda extranjerismos. Sin embargo, siempre hay excepciones: los hablantes ya han dejado de considerar que pádel, de muy reciente incorporación tanto lingüística como lexicográfica, tenga un origen foráneo, aunque no opinan lo mismo de folklore (o folclore / folklor / folclor), documentado en los diccionarios con mucha anterioridad. Es evidente, por lo tanto, que la constante evolución lexicológica hace imposible la actualización lexicográfica completa, independientemente de si se ajusta más o menos a las hipótesis teóricas de importación y consolidación léxica.

\section{Fuentes lexicográficas y corpus}

$\mathrm{CDH}=$ Real Academia Española, Corpus del nuevo diccionario histórico del español, disponible en línea: $<$ http://web.frl.es/CNDHE> [noviembre de 2015]. 
ClAVE = Maldonado GonzÁlez, Concepción (dir.) (2012), Diccionario de uso del español actual, Madrid, Ediciones SM, ed. disponible en línea: <http://clave. smdiccionarios.com $>$ [noviembre 2015].

CORDE = Real ACAdemia Española, Corpus diacrónico del español, disponible en línea: <http://corpus.rae.es/ cordenet.html $>$ [noviembre de 2015].

CORPES XXI = REal ACADEMIa Española, Corpus del español del siglo XXI, disponible en línea: <http://www. rae.es/recursos/banco-de-datos/corpes-xxi $>$ [noviembre de 2015].

CREA = Real ACADEmia Española, Corpus de referencia del español actual, disponible en línea: <http://www. rae.es/recursos/banco-de-datos/crea $>$ [noviembre de 2015].

DA = Asociación de ACAdemias de la Lengua EspañoLA, Diccionario de americanismos, disponible en línea: $<$ http://www.asale.org/recursos/diccionarios/damer> [noviembre de 2015].

DECH = Corominas, Juan y José Antonio Pascual (1980-1991), Diccionario crítico etimológico castellano e hispánico, Madrid, Gredos, 6 vols.

DRAE 2001 = Real Academia Española (2001), Diccionario de la lengua española, 22a ed., Madrid, EspasaCalpe, ed. disponible en línea: <http://lema.rae.es/ drae/> [noviembre de 2015].

DLE 2014 = Real Academia Española (2014), Diccionario de la lengua española, 23a ed., Madrid, EspasaCalpe, ed. disponible en línea: <http://dle.rae.es/> [noviembre de 2015]. 
DPD = ReAl AcAdemia Española (2005), Diccionario panhispánico de dudas, disponible en línea: <http:// www.rae.es/recursos/diccionarios/dpd $>$ [noviembre de 2015].

Real Academia Española, Diccionario de Autoridades (1726), Diccionario de la lengua castellana (1780, 1817, 1869, 1884) o Diccionario de la lengua española (1925, 1936, 1956, 1970, 1984 y 1992) o Diccionario manual e ilustrado de la lengua española (1927, 1950, 1983, 1985 y 1989), obras y eds. disponibles en línea en el NTLLE: <http://ntlle.rae.es/ntlle/SrvltGUILoginNtlle> [octubre-noviembre de 2015].

\section{Bibliografía}

Alvar Ezquerra, Manuel (1999a), "El neologismo: caracterización, formación y aceptabilidad”, en José Manuel González, M. ${ }^{a}$ Luisa Montero y Jesús Terrón (eds.), $V$ Jornadas de metodología y didáctica de la lengua española: el neologismo, Cáceres, Universidad de Extremadura, Servicio de Publicaciones, ICE, pp. 39-66.

Alvar Ezquerra, Manuel (dir.) (1999b), Manual de redacción y estilo, Madrid, Istmo (Colección Fundamentos, 142).

Alvar EzQuerra, Manuel (2006 [1994]), La formación de palabras en español, Madrid, Arco/Libros (Cuadernos de Lengua Española, 8). 
Álvarez de Miranda, Pedro (2009), "Neología y pérdida léxica”, en Elena de Miguel (ed.), Panorama de lexicología, Barcelona, Ariel (Ariel Letras), pp. 133-158.

Appel, René y Pieter Muysken (1996), Bilingüismo y contacto de lenguas, Barcelona, Ariel (Ariel Lingüística).

Azorín Fernández, Dolores (2015), "El neologismo en la tradición académica (1780-2014)”, Estudios de Lexicografía, 2, pp. 58-70.

Deroy, Louis (1956), Lemprunt linguistique, París, Société d'Édition «Les Belles Lettres», 141.

Gómez Capuz, Juan (1998), El préstamo lingüístico: conceptos, problemas y métodos, Valencia, Universidad de Valencia (Anejo XXIX de Cuadernos de Filología).

Gómez Capuz, Juan (2004), Préstamos del español: lengua y sociedad, Madrid, Arco/Libros (Cuadernos de Lengua Española, 82).

Gómez Capuz, Juan (2005), La inmigración léxica, Madrid, Arco/Libros (Cuadernos de Lengua Española, 84).

Guerrero-Ramos, Gloria (1997 [1995]), Neologismos en el español actual, Madrid, Arco/Libros (Cuadernos de Lengua Española).

Guerrero-Ramos, Gloria (2013), "El préstamo lingüístico, uno de los principales procedimientos de creación neológica”, Quaderns de Filologia (Estudis lingüístics), XVIII, pp. 115-130.

Guilbert, Louis (1975), La créativité lexicale, París, Larousse.

Haugen, Einar (1950), "The Analysis of Linguistic Borrowing", Language, 26, pp. 210-231. 
Lázaro Carreter, Fernando (1987), "Los medios de comunicación y la lengua española”, en Comisión permanente de la Asociación de Academias de la Lengua Española, Primera reunión de Academias de la Lengua Española sobre El lenguaje y los medios de comunicación (Octubre 1985), Madrid, Aguirre, pp. 29-43.

Lázaro Carreter, Fernando (2003), El nuevo dardo en la palabra, Barcelona, Círculo de Lectores-Santillana Ediciones Generales.

Medina López, Javier (2004 [1996]), El anglicismo en el español actual, Madrid, Arco/Libros (Cuadernos de Lengua Española, 51).

NGLE $=$ Real ACADEmia Española y Asociación de Academias de la Lengua española (2009), Nueva gramática de la lengua española, Madrid, Espasa, vol. I (Morfología y sintaxis I).

Ors, Javier (2014), "Pedro Álvarez de Miranda: «Nacen más palabras de las que mueren»", LARAZÓN.es (Cultura), 16 de octubre de 2014, entrevista disponible en: http://www.larazon.es/cultura/pedro-alvarez-demiranda-nacen-mas-palabras-de-las-que-muerenGA7662282\#.Ttt1s3foyVcgnsT [21/10/2015].

Prat Sabater, Marta y Cristina Buenafuentes de la Mata (2008), "Metodología docente para el aprendizaje de una competencia transversal: el dominio oral y escrito de la lengua", en $V$ Congreso Internacional de Docencia Universitaria e Innovación: "El cambio en la cultura docente universitaria", Lleida, V CIDUI (edición en CD-ROM), pp. 1-14. 
Prat Sabater, Marta y Sonia Sierra Infante (2011), "Los neologismos en la sociedad de la información: análisis de su presencia y ausencia en las fuentes lexicográficas escolares", Revista Teoría de la Educación: Educación y Cultura en la Sociedad de la Información, 12 (3), pp. 141-164.

Pratt, Chris (1980), El anglicismo en el español peninsular contemporáneo, Madrid, Gredos (BRH, Estudios y ensayos, 308).

Rey-Debove, Josette (1973), "La semiotique de l'emprunt lexical", Travaux de Linguistique et de Littérature, XI, pp. 109-123.

Sala, Marius (1998), Lenguas en contacto, Madrid, Gredos (BRH, Estudios y Ensayos, 409).

Seco, Manuel (1977), "El léxico de hoy", en Rafael Lapesa (coord.), Comunicación y lenguaje, Madrid, Karpos (Instituto de Ciencias del Hombre, 4).

Villar Díaz, Maa. Belén (2009), "Modelos estructurales", en Elena de Miguel (ed.), Panorama de lexicología, Barcelona, Ariel (Ariel Letras), pp. 219-246.

Weinreich, Uriel (1953), Languages in Contact, La Haya, Mouton. 
